\title{
Histoepigenetic analysis of HPV- and tobacco-associated head and neck cancer identifies both subtype-specific and common therapeutic targets despite divergent microenvironments
}

\author{
Ivenise Carrero $^{1,2} \cdot$ Hsuan-Chen Liu ${ }^{3,4} \cdot$ Andrew G. Sikora $^{4} \cdot$ Aleksandar Milosavljevic $^{1,2,5}$ \\ Received: 18 June 2018 / Revised: 7 December 2018 / Accepted: 11 December 2018 / Published online: 17 January 2019 \\ (c) The Author(s) 2019. This article is published with open access
}

\begin{abstract}
Although head and neck squamous cell carcinoma (HNSCC) has in the past been largely associated with tobacco use, human papillomavirus $(\mathrm{HPV}+)$ oropharynx cancer has in recent years emerged as the fastest growing type of HNSCC. Patients with HPV + HNSCC have a better prognosis; however, the 5-year survival for both HPV + and HPV - subtypes with recurrent or metastatic disease is poor. To gain insights into the tumor microenvironments of both HNSCC subtypes and identify potential therapeutic targets, we performed epigenomic deconvolution on 580 HNSCC samples from the TCGA dataset. Deconvolution revealed distinct molecular and histoepigenetic profiles of the two tumor subtypes, including their cellular composition, epigenomic profiles and gene expression for constituent cell types, and potential cancer cell-specific targets. Our analyses show that high abundance of both CD8 T-cells and B-cells explains better prognosis in HPV+ HNSCC. Deconvolution of gene expression profiles revealed higher expression of the immunotherapy target PD-1 in HPV+ immune cells compared to HPVcells, suggesting that HPV + tumors may preferentially benefit from PD-1 targeted therapy. Further analyses identified HPV+ and HPV - cancer cell surface proteins that can also serve as potential targets for therapy. Specifically, Wnt pathway receptor ROR2 is preferentially overexpressed in HPV+ subtypes, suggesting opportunities for development of targeted therapy based on HPV status. In summary, the comprehensive molecular and histoepigenetic analysis of tumor microenvironments by epigenomic deconvolution reveals potential novel biomarkers and targets for precision therapy of HNSCC.
\end{abstract}

\section{Introduction}

Head and Neck Squamous Cell Carcinoma (HNSCC) arises from the squamous epithelial cells in the mucosal lining of the oral cavity [1]. The annual worldwide incidence of

These authors contributed equally: Ivenise Carrero, Hsuan-Chen Liu

Supplementary information The online version of this article (https:// doi.org/10.1038/s41388-018-0659-4) contains supplementary material, which is available to authorized users.

Andrew G. Sikora

Andrew.Sikora@bcm.edu

$\triangle$ Aleksandar Milosavljevic

amilosav@bcm.edu

1 Molecular and Human Genetics Department, Baylor College of Medicine, Houston, TX, USA

2 Epigenome Center, Baylor College of Medicine, Houston, TX, USA
550,000 cases makes it the sixth most common cancer [2]. HNSCC can be divided into HPV+ subtype caused by Human Papillomavirus infection, and HPV - subtype that is largely attributable to tobacco and alcohol consumption [3]. While the incidence of HPV - HNSCC is higher worldwide than $\mathrm{HPV}+$, the rate of occurrence of $\mathrm{HPV}+$ is on the rise in the United States [4,5]. Despite the advancement in new treatments for both subtypes of HNSCC, the 5-year survival rate for head and neck malignancies remains around $65 \%$ [6]. While the HPV+ HNSCC patients have a better

3 Translational Biology and Molecular Medicine Program, Baylor College of Medicine, Houston, TX, USA

4 Department of Otolaryngology-Head and Neck Surgery, Baylor College of Medicine, Houston, TX, USA

5 Program in Quantitative and Computational Biosciences, Baylor College of Medicine, Houston, TX, USA 
prognosis and survival $[5,7]$, the factors that contribute to this difference are still poorly understood.

Targeted therapy has in the past few decades become an established approach for cancer treatment [8]. Monoclonal antibody treatment targeting the epidermal growth factor receptor (EGFR) has been approved for HNSCC, with resistance frequently developing [9]. Immunotherapy targeting PD-1 has been approved for certain subsets of recurrent/refractory HNSCC. However, only a minority of HNSCC patients respond to anti-PD-1 or anti-PD-L1 antibody therapies [10]. The full spectrum of potential targets in HNSCC remains to be identified.

Comprehensive molecular profiling of HPV + and HPV - HNSCC tumors revealed distinct molecular etiologies, with a high percentage of HPV - tumors carrying TP53 mutations, while a high percentage of HPV+ tumors showing overexpression of p16INK4a [11, 12]. Most recently it was shown that HPV infection not only affects gene expression patterns in HNSCC, but also DNA methylation patterns $[13,14]$. While the emerging information about molecular differences and commonalities between the two tumor types suggests the presence of subtype-specific targets and therapy responses, these differences are yet to be fully mapped and translated into precision therapies that are informed by HPV status.

To help develop precision therapies for HPV + and HPV - HNSCC and to elucidate the factors that affect their prognosis, we set out to identify differences and similarities in HPV + and HPV - HNSCC tumors at the molecular, cellular and microenvironment levels. We also identify potential new biomarkers or therapy targets. One of our target groups are cell surface proteins, which represent a group of genes widely used to develop targeted therapies [15-17] and immunotherapy treatments [18, 19].

Identification of therapy targets in tumors represents a challenge due to the presence of different cell types in the tumor microenvironment. Previous studies have attempted to look for targets in HPV+ and HPV - HNSCC without taking into consideration the complexity of the cell type composition of tumors [20]. These studies on bulk tumor may lead to both false positives and false negatives as the intercellular differences are confounded by differences in cellular composition. Physical separation methods such as laser capture microdissection and cell sorting can isolate the different cell types in the tumor, however, their throughput is limited [21]. Attempts to address the problem computationally include in silico deconvolution using gene expression or epigenomic (DNA methylation) profiles. The main obstacle in applying current gene expression-based deconvolution methods is the lack of highly accurate gene markers for cells other than leukocytes [22-24]. Some epigenomic deconvolution methods detect only subsets of cell types present within the tumor tissue $[25,26]$. To address these problems, we apply the recently developed epigenomic deconvolution (EDec) method [27] to the HNSCC dataset from The Cancer Genome Atlas (TCGA) to comprehensively estimate the histoepigenetic profiles of tumors, including cell type proportions, methylation profiles and gene expression profiles of constituent cell types in both $\mathrm{HPV}+$ and HPV - HNSCC.

\section{Results}

\section{Epigenomic deconvolution identifies constituent cell types and their methylation profiles}

Stage 1 of the EDec method (Fig. 1a) revealed five constituent cell types, their epigenomic profiles, and provided estimates of proportions of each of the five cell types in each tumor sample. To establish the identity of the constituent cell types their estimated methylation profiles were correlated with the reference methylation profiles of known cell types from GEO (Fig. 1b). High correlation suggested that one of the profiles belongs to an immune cell type, one to normal epithelial/stromal and three to distinct cancer epithelial cell types (Fig. 2a).

The estimated proportions of constituent cell-types in each tumor sample were next validated by $H \& E$ staining data from the HNSCC component of the cancer digital slide archive (CDSA) from Emory University. CDSA includes 255 HNSCC samples from the TCGA collection and provides proportions of stromal, epithelial, and cancer cells for each tumor biopsy [28]. Since the cell type proportion of stromal and normal epithelial could not be stably deconvoluted, for the purpose of comparison, we combined their CDSA proportion estimates. Average cell proportions estimated by EDec and H\&E staining were similar: the average cancer cell proportion as estimated by EDec is 0.73 vs 0.77 by $H \& E$ staining; and the stromal/normal epithelial cell proportion estimated by EDec was 0.26 vs 0.21 by $\mathrm{H} \& \mathrm{E}$ staining (Fig. 2b). Sample-to-sample proportion correlation between EDec and H\&E was high for a majority of samples, with, $62 \%$ of the samples showing correlation of cancer cell proportions at $r=0.72$ level $(p$-value $=4.06 \mathrm{E}$ $-26)$ and stromal/normal epithelial proportions at $r=0.73$ level ( $p$-value $=2.42 \mathrm{E}-27$ ) (Fig. 2c). This level of correlation validates that EDec performed as expected on this dataset.

\section{Deconvolution reveals significant epigenomic differences between HPV + and HPV - cancer cells}

Analysis of cell type proportions for $72 \mathrm{HPV}+\mathrm{HNSCC}$, $243 \mathrm{HPV}-\mathrm{HNSCC}$ and 50 adjacent normal samples shows that, as expected, the 50 normal samples have higher 
a

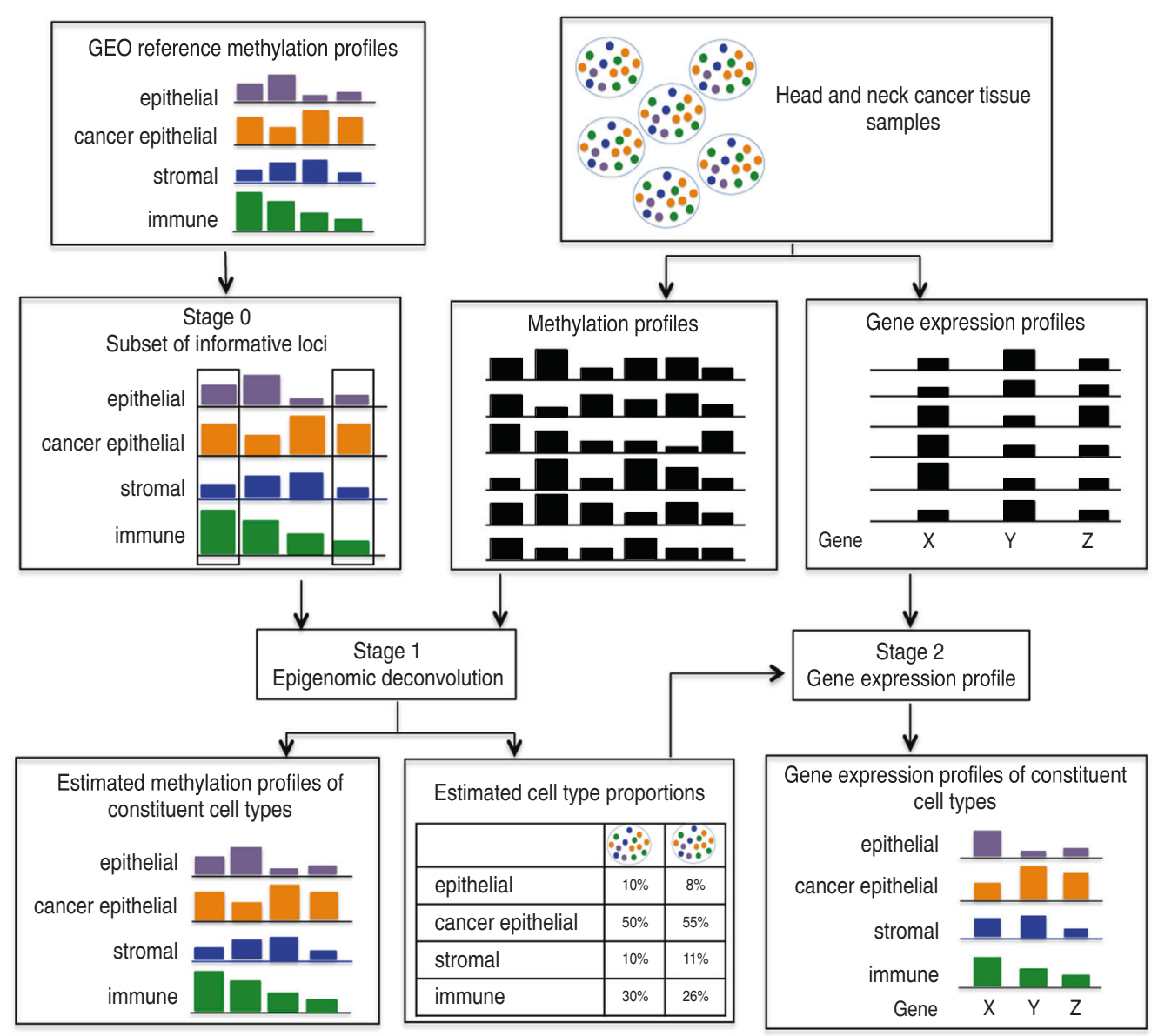

b

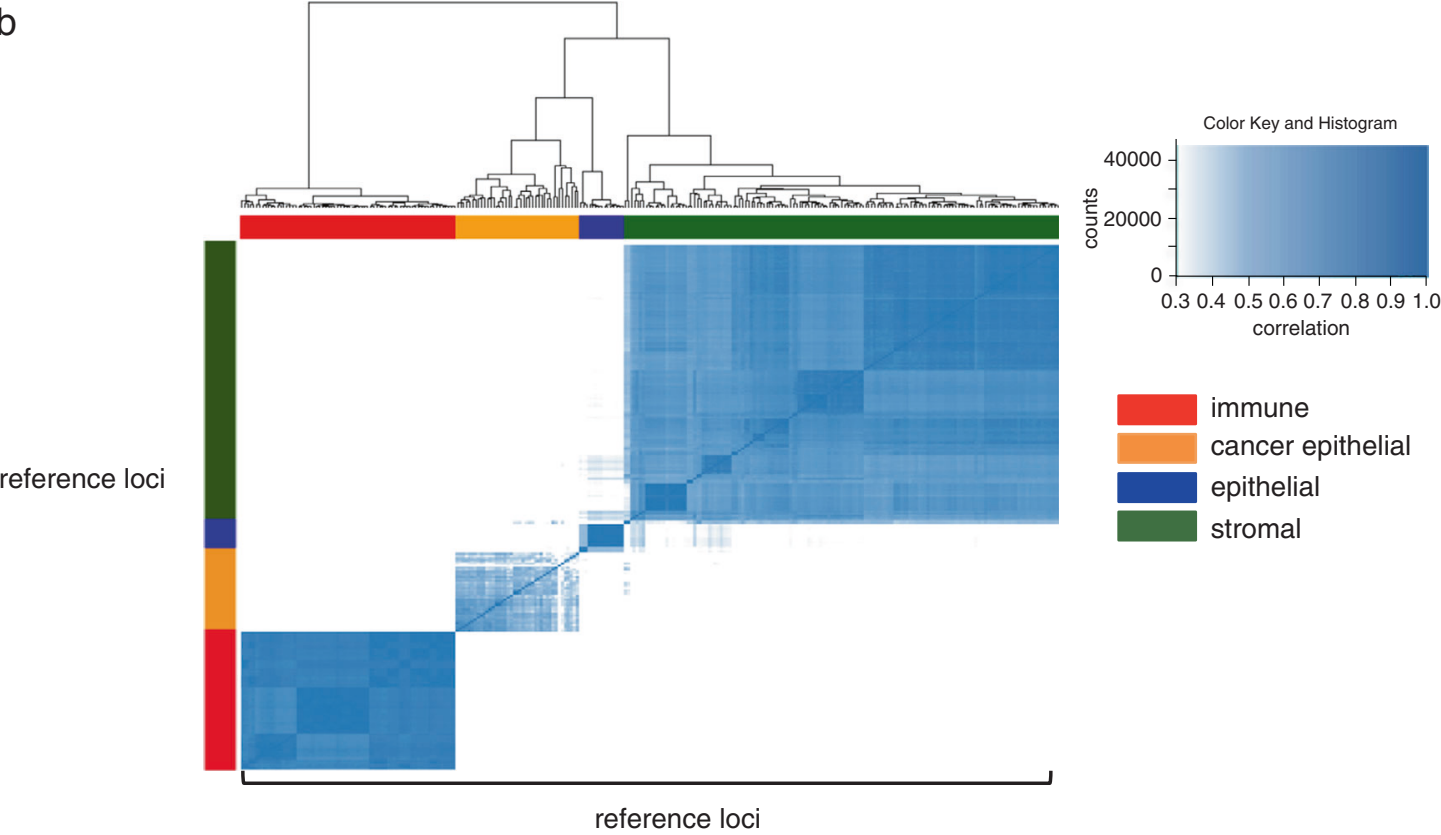

proportion of stromal/epithelial cells and negligible proportions of cancer cells compared to the tumor samples. Deconvolution models the cancer fraction by three distinct cancer cell types, one corresponding to HPV + HNSCC, another to HPV - HNSCC and one present in both (Fig. $2 \mathrm{~d})$. The dendrogram of the three deconvoluted cancer cell 
Fig. 1 a EDec consist of three stages (stages 0,1, and 2). In stage 0, a set of reference DNA methylation profiles (in our case from the GEO database) is used to select a set of informative loci that show methylation level differences between the cell types expected to be observed in the tumor. In stage 1, the tumor DNA methylation profiles (in our case the HNSCC portion of TCGA) are used to estimate both the average methylation profiles of constituent cell types across tumor samples and cell type proportions in each sample. In stage 2, the estimated cell type proportions as well as the gene expression profiles from the same set of samples (HNSCC portion of TCGA) are used to estimate the gene expression profiles of constituent cell types. b Heat map representing the high correlation of the informative reference loci from stage 0 with the constituent cell types from the reference methylation profiles

methylation profiles (Fig. 2a) shows that the HPV+ methylation profile clusters apart from the other two, suggesting highly distinct epigenetic properties of the HPV+ cancer cell type compared to all other HPV - cancer epithelial cells, consistent with previous findings that HPV + is biologically and epigenetically different from HPVHNSCC [13, 29].

To further explore the epigenetic differences between the $\mathrm{HPV}+$ and HPV - subtypes, we performed differential methylation analysis. We first identified differentially methylated genes using the RnBeads package [30] and then performed gene set enrichment analysis using GSEA [31, 32]. A number of pathways were specifically upregulated and downregulated in HPV + HNSCC (Supplementary Table $1 \mathrm{a}-\mathrm{d})$. Genes regulated by the transcription factors NANOG and MYC were significantly enriched in promoters hypomethylated in HPV + HNSCC, suggesting their activation in this subtype (Supplementary Table 1d). This is consistent with the fact that activation of NANOG and MYC targeted genes is associated with poorly differentiated tumors [33], and the poorly differentiated histology of HPV + HNSCC tumors [3]. In addition, we observed enrichment of genes involved in cell cycle regulation. In contrast, the genes known to be downregulated in nasopharyngeal carcinoma showed gene body hypomethylation, consistent with their silencing (Table 1, supplementary Table 1b).

The set of genes with hypermethylated promoters showed enrichment for pathways involved in cancer, such as receptor signaling pathways and histone modifications. We also observed enrichment for genes targeted by the Polycomb proteins SUZ12 and EED, which are known to be repressed in histologically poorly differentiated tumors [33] (Supplementary Table 1c). The set of genes with hypermethylated gene bodies showed enrichment for pathways involved in cancer, including histone modification, cell adhesion, and cell development. Another set of enriched genes were RB1 targets, consistent with the mechanism of carcinogenesis of HPV, where the oncogenic HPV protein E7 repress the Retinoblastoma protein $(\mathrm{Rb})$ and promotes cell proliferation [34] (Supplementary Table 1a).
We also observed enrichment of genes related to immune components including CD8 T-cells, suggesting interaction between cancer cells and immune cells in HPV + HNSCC (Table 2).

\section{Higher proportion of CD8 + T-cells and B-cells accounts for better prognosis in HPV + HNSCC}

Previous studies have shown that HPV + has higher T-cell infiltration than HPV - HNSCC, however they have not compared tumor profiles with those of normal samples [10]. Our analyses show that both HPV + and HPV - HNSCC show higher proportion of immune cell types compared to healthy tissue (Fig. 2d). To examine differences in relative proportions of immune cell types between $\mathrm{HPV}+, \mathrm{HPV}-$ HNSCC, and normal tissue in more detail, we applied the in silico tool MCP counter [35]. Compared to normal samples, both HPV + and HPV - in fact show relative depletion of Tcells, consistent with the known immunosuppressive microenvironment of HNSCC [36]. However, HPV+ tumors showed significantly higher abundance of CD8 Tcells compared to not only HPV - but also to normal samples, consistent with previous findings [10]. Moreover, HPV + HNSCC also showed high abundance of B-lineage cells compared to both HPV - and normal samples (Fig. 3a).

Consistent with previous studies [3, 37], Kaplan-Meier analysis showed better survival for $\mathrm{HPV}+$ compared to HPV - HNSCC patients (Supplementary Fig. 1a). However, using multivariate Cox regression we discovered that HPV status loses significance after adjusting for the abundance of CD8 T-cells and/or B-cells along with other factors. We then analyzed the prognostic impact of the abundance of CD8 T-cells and B-cells by controlling for HPV status, age of diagnosis and cancer stage using multivariate Cox regression. In the presence of those covariates, tumors with high abundance of CD8 T-cells and B-lineage cells are associated with increased survival $(\mathrm{HR}=0.46, p$-value $=$ $0.014,95 \%$ CI $0.249-0.857$, and $\mathrm{HR}=0.45, p$-value $=$ 0.010 , 95\% CI 0.248-0.828, respectively) (Fig. 3b, Supplementary Table 2). Interestingly, multivariate Cox regression performed considering CD8 T-cells and B-cell abundances together suggests that these two variables do not provide information about survival independently of each other (Fig. 3c) and are thus largely interchangeable as survival indicators.

To further explore the relation between HPV status and the abundance of CD8 T-cells and B-cells we applied generalized linear modeling. We observed that HPV status is significantly associated with both CD8 T-cell and B-cell abundance $\quad(p$-value $=1.82 \mathrm{E}-01 \quad$ and $\quad p$-value $=0.01$, respectively) (Supplementary Fig. 1b). Additionally, we examined the collinearity between HPV status, CD8 T-cell, 


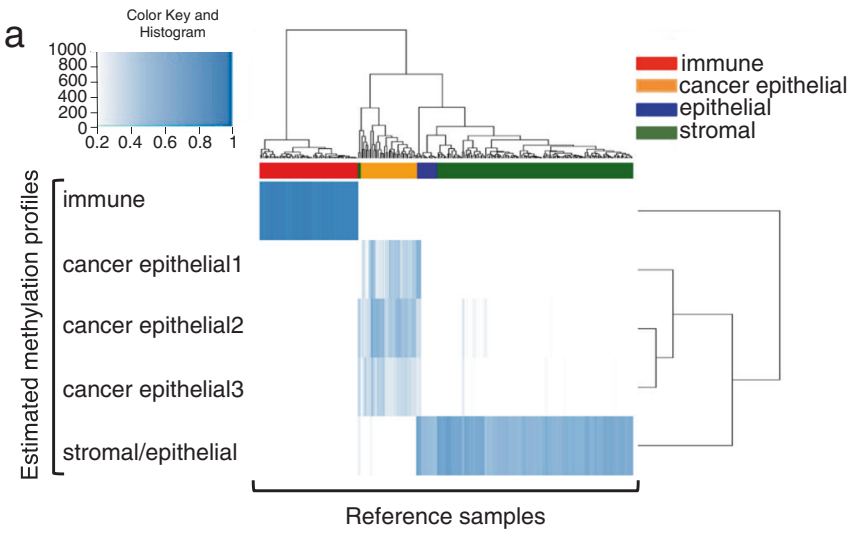

b

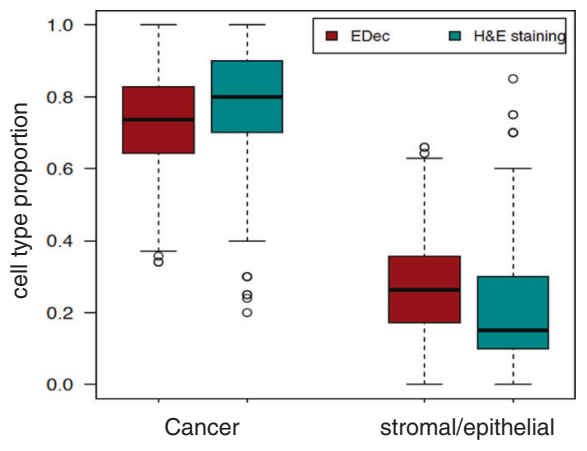

C
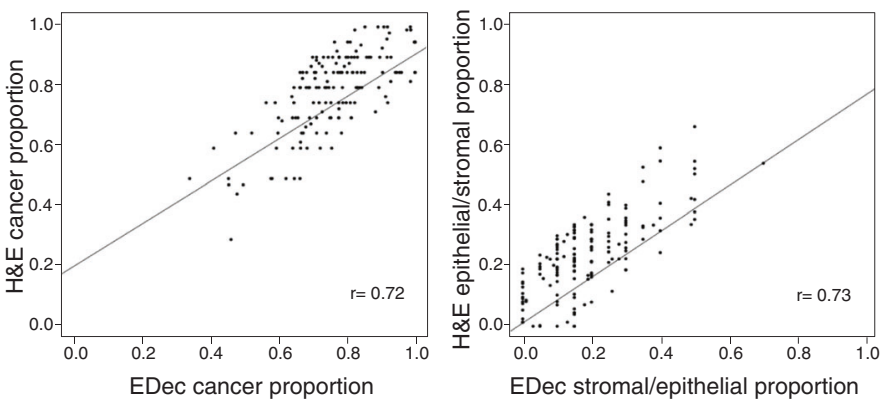

d

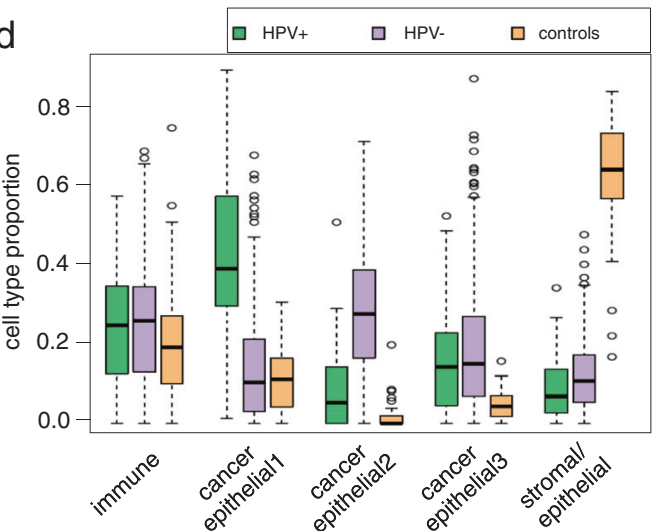

Fig. 2 a Heat map showing the correlation between the head and neck methylation profiles estimated by EDec and the reference methylation profiles. b Boxplot comparing the cell type proportion of cancer cells and stromal/epithelial cells between EDec and H\&E staining. c

and B-cell abundance by calculating the variance inflation factor (VIF) in our generalized linear model. We observed that both B-cells and CD8 T-cells showed low collinearity $(\mathrm{VIF}=1.0829$ and $\mathrm{VIF}=1.0828$, respectively $)$, suggesting that our model is stable. To further explore the relationship between high abundance of CD8 T-cells and high abundance of B-cells, we also performed pairwise correlation between the two variables. We observed an imperfect but significant positive linear correlation between the abundance of CD8 T-cells and B-cells (Pearson's $r=0.27$, $p$-value $=1.675 \mathrm{E}-06,95 \% \mathrm{CI}=0.16099-0.3674) \quad($ Supplementary Fig. 1c).

To further establish whether immune compartment differences between HPV + and HPV - HNSCC account for the differences in prognosis between the two subtypes, we compared survival of TCGA patients in the top and bottom immune cell type abundance quartiles using Kaplan-Meier analysis. Consistent with previous studies, patients with high (top 25\%) abundance of CD8- T-cells showed better
Scatterplot showing the correlation between EDec and H\&E staining for cancer cells and stromal/epithelial cells. d Proportions of constituent cell types for TCGA HNSCC dataset estimated by EDec, comparing $\mathrm{HPV}+, \mathrm{HPV}-$ and controls

survival than patients with low (bottom 25\%) abundance of CD8 T-cells ( $p$-value $=0.0016)$. Moreover, we observed the same survival pattern when comparing tumors with high vs low abundance of B-lineage cells $(p$-value $=0.0055)$ (Fig. 3d).

Since HPV + HNSCC is more common in lymphoid-rich regions (oropharyngeal, tonsils, and base of tongue), we asked if the abundance of CD8 T-cells and B-cells in HPV+ HNSCC might be a result of confounding due to the tendency of HPV + HNSCC to occur in those regions. Toward this goal, we compared the immune cell-type proportion differences between $\mathrm{HPV}+$ and $\mathrm{HPV}-\mathrm{HNSCC}$ tumors present only in these lymphoid-rich regions. HPV+ HNSCC tumors showed a significantly higher abundance of CD8 T-cells and B-cells compared to HPV- HNSCC (Supplementary Fig. 1d), suggesting that the higher abundance of CD8 T-cells and B-cells in HPV+ HNSCC cannot be explained by their preferential localization in lymphoidrich regions. 
Table 1 Enriched pathways in hypomethylated promoters and gene bodies

\begin{tabular}{|c|c|c|}
\hline Pathways & $\begin{array}{l}\text { Hypomethylated } \\
\text { gene body }\end{array}$ & $\begin{array}{c}\text { Hypomenthylated } \\
\text { promoter }\end{array}$ \\
\hline \multicolumn{3}{|l|}{ PUJANA_BRCA1_PCC_NETWORK } \\
\hline \multicolumn{3}{|l|}{ PUJANA_CHEK2_PCC_NETWORK } \\
\hline \multicolumn{3}{|l|}{ PUJANA_ATM_PCC_NETWORK } \\
\hline \multicolumn{3}{|l|}{ LEE_BMP2_TARGETS_DN } \\
\hline \multicolumn{3}{|l|}{ BENPORATH_NANOG_TARGETS } \\
\hline \multicolumn{3}{|l|}{ DANG_BOUND_BY_MYC } \\
\hline \multicolumn{3}{|l|}{ BENPORATH_MYC_MAX_TARGETS } \\
\hline \multicolumn{3}{|l|}{ FISCHER_DREAM_TARGETS } \\
\hline \multicolumn{3}{|l|}{ GARY_CD5_TARGETS_DN } \\
\hline \multicolumn{3}{|l|}{ NUYTTEN_EZH2_TARGETS_DN } \\
\hline \multicolumn{3}{|l|}{ KINSEY_TARGETS_OF_EWSR1_FLII_FUSION_UP } \\
\hline \multicolumn{3}{|l|}{ MARSON_BOUND_BY_E2F4_UNSTIMULATED } \\
\hline \multicolumn{3}{|l|}{ MARSON_BOUND_BY_FOXP3_UNSTIMULATED } \\
\hline \multicolumn{3}{|l|}{ MARSON_BOUND_BY_FOXP3_STIMULATED } \\
\hline \multicolumn{3}{|l|}{ DODD_NASOPHARYNGEAL_CARCINOMA_DN } \\
\hline \multicolumn{3}{|l|}{ CAIRO_HEPATOBLASTOMA_CLASSES_UP } \\
\hline \multicolumn{3}{|l|}{ GO_CELL_CYCLE } \\
\hline \multicolumn{3}{|l|}{ GO_REGULATION_OF_CELL_CYCLE } \\
\hline \multicolumn{3}{|l|}{ GRAESSMANN_APOPTOSIS_BY_DOXORUBICIN_DN } \\
\hline \multicolumn{3}{|l|}{ GO_REGULATION_OF_ORGANELLE_ORGANIZATION } \\
\hline \multicolumn{3}{|l|}{ GO_ENDOPLASMIC_RETICULUM } \\
\hline \multicolumn{3}{|l|}{ GO_NUCLEAR_OUTER_MEMBRANE_ENDOPLASMIC_RETICULUM_MEMBRANE_NETWORK } \\
\hline \multicolumn{3}{|l|}{ GO_NCRNA_METABOLIC_PROCESS } \\
\hline \multicolumn{3}{|l|}{ GO_CARBOHYDRATE_DERIVATIVE_METABOLIC_PROCESS } \\
\hline \multicolumn{3}{|l|}{ KRIGE_RESPONSE_TO_TOSEDOSTAT_24HR_DN } \\
\hline \multicolumn{3}{|l|}{ KRIGE_RESPONSE_TO_TOSEDOSTAT_6HR_DN } \\
\hline \multicolumn{3}{|l|}{ TIEN_INTESTINE_PROBIOTICS_24HR_UP } \\
\hline \multicolumn{3}{|l|}{ GO_POLY_A_RNA_BINDING } \\
\hline \multicolumn{3}{|l|}{ GO_RNA_BINDING } \\
\hline \multicolumn{3}{|l|}{ GO_RIBONUCLEOTIDE_BINDING } \\
\hline \multicolumn{3}{|l|}{ GO_ENZYME_BINDING } \\
\hline GSE6259_FLT3L_INDUCED_33D1_POS_DC_VS_BCELL_UP & & \\
\hline
\end{tabular}

To further corroborate the higher abundance of CD8 Tcells and B-cells in HPV + compared to HPV - HNSCC, we used an independent dataset from Zhang et al. (2016) [38], consisting of $18 \mathrm{HPV}+$ and $18 \mathrm{HPV}-\mathrm{RNA}$-seq profiles from pre-treated HNSCC. Consistent with our analyses of TCGA head and neck cancer data, MCP counter analysis of HPV+ tumors showed a significantly higher abundance of CD8 Tcells and B-cells compared to HPV- HNSCC (Fig. 3e).

\section{Expression of PD-1 and CTLA4 in the immune} compartment may predict differential and shared response to immunotherapy in $\mathrm{HPV}+$ and $\mathrm{HPV}-$ HNSCC

We next compared the gene expression profiles (deconvoluted by EDec) of the immune fraction in HPV + and HPV - HNSCC. As expected, marker immune genes for T-cells 
Table 2 Enriched pathways in hypermethylated promoters and gene bodies

\begin{tabular}{|c|c|c|}
\hline Pathways & $\begin{array}{l}\text { Hypermethylated } \\
\text { gene body }\end{array}$ & $\begin{array}{c}\text { Hypermethylated } \\
\text { promoter }\end{array}$ \\
\hline \multicolumn{3}{|l|}{ BENPORATH_SUZ12_TARGETS } \\
\hline \multicolumn{3}{|l|}{ BENPORATH_EED_TARGETS } \\
\hline \multicolumn{3}{|l|}{ BENPORATH_PRC2_TARGETS } \\
\hline \multicolumn{3}{|l|}{ CHICAS_RB1_TARGETS_CONFLUENT } \\
\hline \multicolumn{3}{|l|}{ GO_CELL_DEVELOPMENT } \\
\hline \multicolumn{3}{|l|}{ GO_CELL_MORPHOGENESIS_INVOLVED_IN_DIFFERENTIATION } \\
\hline \multicolumn{3}{|l|}{ GO_SYSTEM_PROCESS } \\
\hline \multicolumn{3}{|l|}{ GO_NEUROLOGICAL_SYSTEM_PROCESS } \\
\hline \multicolumn{3}{|l|}{ GO_BIOLOGICAL_ADHESION } \\
\hline \multicolumn{3}{|l|}{ GO_SIGNAL_TRANSDUCER_ACTIVITY } \\
\hline \multicolumn{3}{|l|}{ GO_DETECTION_OF_STIMULUS } \\
\hline \multicolumn{3}{|l|}{ GO_G_PROTEIN_COUPLED_RECEPTOR_SIGNALING_PATHWAY } \\
\hline \multicolumn{3}{|l|}{ GO_SENSORY_PERCEPTION } \\
\hline \multicolumn{3}{|l|}{ GO_SIGNALING_RECEPTOR_ACTIVITY } \\
\hline \multicolumn{3}{|l|}{ GO_G_PROTEIN_COUPLED_RECEPTOR_ACTIVITY } \\
\hline \multicolumn{3}{|l|}{ REACTOME_GPCR_DOWNSTREAM_SIGNALING } \\
\hline \multicolumn{3}{|l|}{ GO_RECEPTOR_ACTIVITY } \\
\hline \multicolumn{3}{|l|}{ REACTOME_SIGNALING_BY_GPCR } \\
\hline \multicolumn{3}{|l|}{ GO_SENSORY_PERCEPTION_OF_CHEMICAL_STIMULUS } \\
\hline \multicolumn{3}{|l|}{ GO_OLFACTORY_RECEPTOR_ACTIVITY } \\
\hline \multicolumn{3}{|l|}{ KEGG_OLFACTORY_TRANSDUCTION } \\
\hline \multicolumn{3}{|l|}{ GO_PRESYNAPSE } \\
\hline \multicolumn{3}{|l|}{ REACTOME_HEPARAN_SULFATE_HEPARIN_HS_GAG_METABOLISM } \\
\hline \multicolumn{3}{|l|}{ BENPORATH_ES_WITH_H3K27ME3 } \\
\hline \multicolumn{3}{|l|}{ MIKKELSEN_ES_ICP_WITH_H3K4ME3_AND_H3K27ME3 } \\
\hline \multicolumn{3}{|l|}{ MIKKELSEN_MEF_ICP_WITH_H3K27ME3 } \\
\hline \multicolumn{3}{|l|}{ MIKKELSEN_IPS_ICP_WITH_H3K4ME3_AND_H327ME3 } \\
\hline \multicolumn{3}{|l|}{ MEISSNER_BRAIN_HCP_WITH_H3K4ME3_AND_H3K27ME3 } \\
\hline \multicolumn{3}{|l|}{ GSE37301_HEMATOPOIETIC_STEM_CELL_VS_CD4_TCELL_DN } \\
\hline GSE3039_ALPHAALPHA_VS_ALPHABETA_CD8_TCELL_DN & & \\
\hline GSE8835_CD4_VS_CD8_TCELL_CLL_PATIENT_UP & & \\
\hline GSE10239_KLRG1INT_VS_KLRG1HIGH_EFF_CD8_TCELL_DN & & \\
\hline GSE14769_UNSTIM_VS_20MIN_LPS_BMDM_UP & & \\
\hline GSE27670_CTRL_VS_BLIMP1_TRANSDUCED_GC_BCELL_DN & & \\
\hline GSE28726_NAIVE_VS_ACTIVATED_VA24NEG_NKTCELL_DN & & \\
\hline RIGGI_EWING_SARCOMA_PROGENITOR_DN & & \\
\hline RODRIGUES_THYROID_CARCINOMA_ANAPLASTIC_DN & & \\
\hline
\end{tabular}


a Immune cell type composition of HPV+ versus HPVHNSCC from TCGA

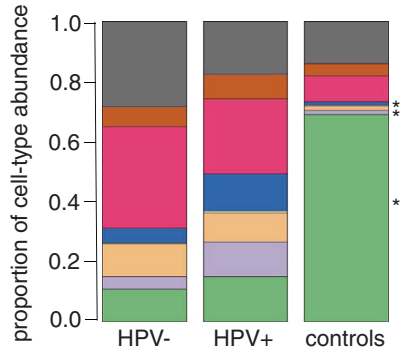

$\square$ Neutrophils

$\square$ Myeloid dendritic cells $\square$ Monocytic lineage

$B$ lineage cells

$\square$ NK cells

$\square$ Cytotoxic lymphocytes

CD8 T-cells

$\square$ T-cells

C

\begin{tabular}{lccc}
\multicolumn{4}{c}{ Cox analysis including CD8 T-cells and B-cells } \\
\hline Variables & $\begin{array}{c}\text { Hazard } \\
\text { Ratio }\end{array}$ & p-value & $\begin{array}{c}95 \% \\
\text { Cl }\end{array}$ \\
\hline CD8 T-cells & 0.58 & 0.129 & $0.303-1.294$ \\
$\begin{array}{l}\text { B-cells } \\
\begin{array}{l}\text { Age of } \\
\text { diagnosis }\end{array}\end{array}$ & 0.63 & 0.207 & $0.283-1.174$ \\
HPV status & 1.03 & 0.002 & $1.010-1.047$ \\
Disease stage & 1.30 & 0.016 & $1.050-1.617$ \\
\hline
\end{tabular}

d

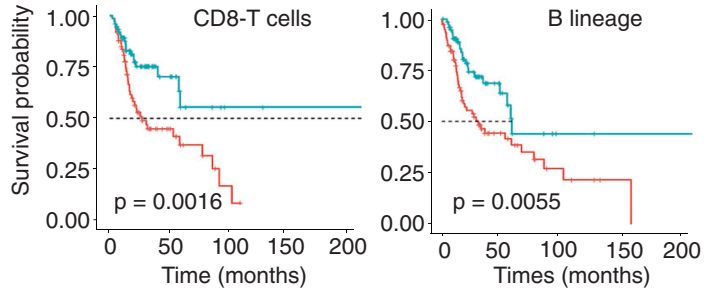

cell type abundance - bottom $25 \% \div$ top $25 \%$

g

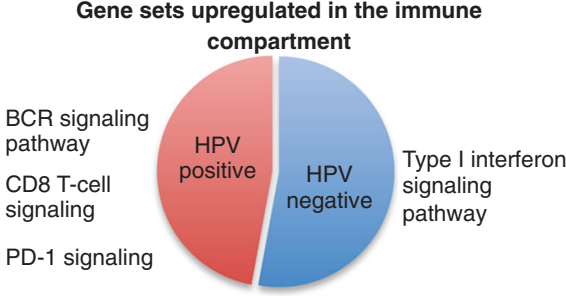

b

\begin{tabular}{lccc}
\hline \multicolumn{4}{c}{ Cox analysis for high abundance of CD8 T-cells } \\
\hline Variables & $\begin{array}{c}\text { Hazard } \\
\text { Ratio }\end{array}$ & p-value & $\begin{array}{c}95 \% \\
\text { Cl }\end{array}$ \\
\hline CD8 T-cells & 0.46 & 0.014 & $0.249-0.857$ \\
Age of diagnosis & 1.03 & 0.003 & $1.009-1.045$ \\
HPV status & 1.38 & 0.312 & $0.741-2.555$ \\
Disease stage & 1.26 & 0.029 & $1.025-1.556$ \\
\hline
\end{tabular}

\begin{tabular}{lccc}
\hline \multicolumn{3}{c}{ Cox analysis for high abundance of B-cells } \\
\hline Variables & $\begin{array}{c}\text { Hazard } \\
\text { Ratio }\end{array}$ & p-value & $\begin{array}{c}95 \% \\
\text { Cl }\end{array}$ \\
\hline B cells & 0.45 & 0.010 & $0.248-0.828$ \\
Age of diagnosis & 1.03 & 0.002 & $1.010-1.046$ \\
HPV status & 1.41 & 0.273 & $0.764-2.592$ \\
Disease stage & 1.32 & 0.012 & $1.063-1.632$ \\
\hline
\end{tabular}

e Immune cell type composition of HPV+ versus HPV-

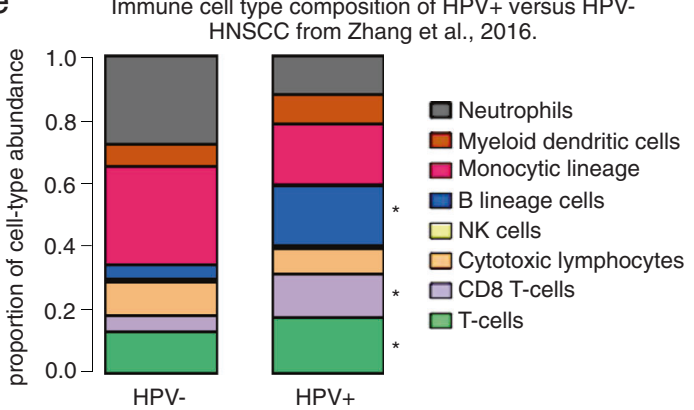

f

B-cells gene markers
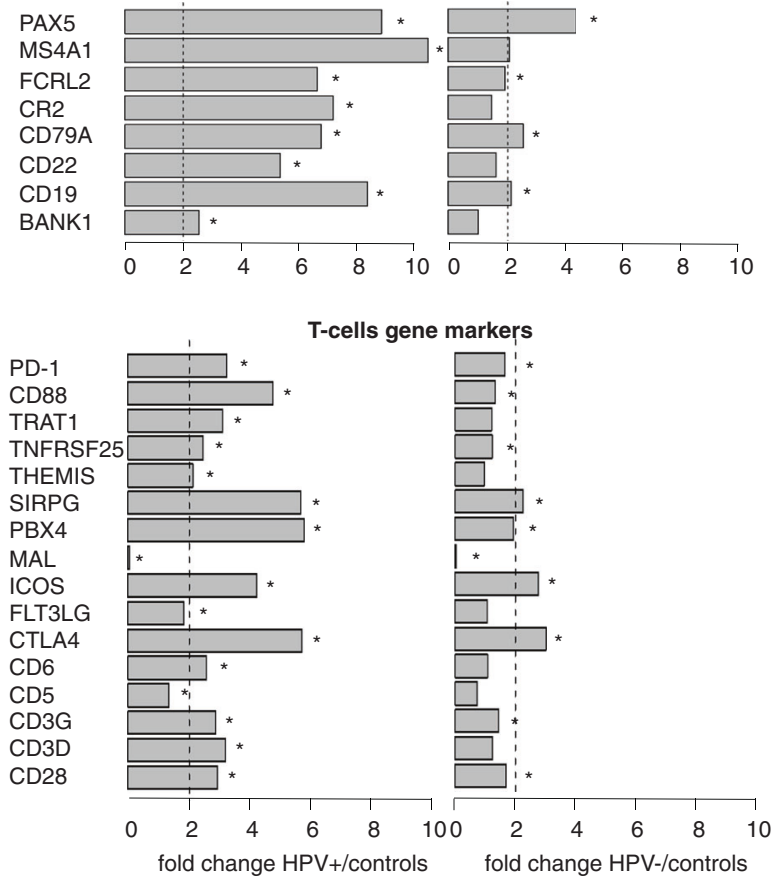

$=3.99, p$-value $=2.98 \mathrm{E}-07)$ and HPV - HNSCC (fold change $=2.5, p$-value $=0.004)$. In contrast, PD-1 (PDCD1) is significantly overexpressed only in HPV + tumors (fold and B-cells were more highly expressed in HPV + HNSCC tumors compared to HPV - tumors (Fig. 3f). Interestingly, CTLA4 was highly expressed in both HPV + (fold change 
Fig. 3 a Bar plot representing the immune cell type composition of $\mathrm{HPV}+, \mathrm{HPV}-\mathrm{HNSCC}$, and controls. b Multivariable Cox regression for CD8 T-cells and B lineage indicating their significant independent prognostic values after correction of covariates. c Multivariable Cox regression analysis showing that CD8 $\mathrm{T}$-cell and $\mathrm{B}$-cell abundance are not independent prognostic factors. d Kaplan-Meier plot showing the significant difference in prognosis for high vs low abundance of CD8 T-cells and B lineage. e Bar plot showing the immune cell-type composition with an independent RNA-seq dataset. f Bar plot showing the fold change of expression of T-cells and B-cells gene markers in HPV + and HPV - HNSCC. g Summary of gene set enrichment analysis for upregulated immune genes in HPV + and HPV - HNSCC

change $=3.21, p$-value $=0.006)$. This finding is interesting in light of the clinical trials targeting PD-1 in HNSCC (regardless of HPV status) that show that only a subset of patients show response [10]. Our results are also consistent with the improved response of $\mathrm{HPV}+\mathrm{HNSCC}$ tumors to anti-PD-1 therapy observed in some clinical trials [39]. In contrast, our results suggest that immunotherapy targeting CTLA-4 might show comparable response for both subtypes.

\section{Gene set enrichment analysis corroborates higher CD8 + T-cell and B-cell infiltration and PD-1 overexpression in HPV + tumors}

To gain further insights into the immunological differences between HPV + and HPV - tumors, we next compared the gene expression profiles in the immune compartment estimated by EDec between $\mathrm{HPV}+, \mathrm{HPV}$ - and normal samples. We performed gene set enrichment analysis [31] on the immune gene set differentially expressed in $\mathrm{HPV}+$ and HPV - HNSCC (Supplementary Table 3a-c). Consistent with the high abundance of $\mathrm{CD} 8-\mathrm{T}$ cells in $\mathrm{HPV}+$ HNSCC, we observed enrichment of pathways involved in CD8 T-cell signaling. Moreover, consistent with high abundance of B cells, we observed enrichment of pathways for B-cell receptor (BCR) signaling. PD-1 signaling pathways were enriched in HPV $+\mathrm{HNSCC}$, consistent with the expression of PD-1 itself. In the case of HPV-, we observed enrichment for regulation and cellular response to type I interferon (Fig. 3g, Supplementary Table 4a-c).

\section{Deconvolution analysis reveals overexpressed cell surface proteins in HNSCC cancer cells}

Because of their accessibility, cancer cell surface proteins are potential targets for therapy using both antibodies and small molecules. We therefore analyzed the expression of cell surface proteins for HPV + and HPV - subtypes of HNSCC by estimating the gene expression profiles of cancer cells (EDec stage 2) using the normalized TCGA
HNSCC RNA-seq data. Toward this goal, we combined the three cancer epithelial estimated proportions from EDec stage 1 . EDec stage 2 was independently applied to $72 \mathrm{HPV}$ + and $243 \mathrm{HPV}-\mathrm{HNSCC}$ tumors and 20 normal tissue controls. EDec predicted overexpression (compared to normal epithelial/stromal cells) of 439 genes in HPV +, 449 in HPV - and 163 genes in both HPV + and HPV - cancer cells (Fig. 4a and Supplementary Table 5a-c). To identify the cell surface proteins among those that are overexpressed, we compared our set of overexpressed genes with The Cell Surface Protein Atlas [35]. The analysis revealed 17 cell surface proteins overexpressed in HPV+, 27 in HPV - and nine cell surface proteins overexpressed in both subtypes (Fig. 4a, Table 3).

\section{Gene set enrichment analysis of cell surface proteins suggests cross-talk between cancer and immune cells}

We next performed gene set enrichment analysis on the cell surface genes preferentially overexpressed in $\mathrm{HPV}+$ or HPV - or both HNSCC subtypes. Cell surface genes in HPV - tumors were enriched for Nicotine pathway, consistent with the role of tobacco consumption in HPVHNSCC. Another enriched pathway was cell-cell junction, implicated in the process of epithelial to mesenchymal transition (EMT), leading to invasion and metastasis [40]. Interestingly, we observed enrichment for pathways involving the drug Irinotecan, which has been tested in a clinical trial for HNSCC [41]. Though the trial failed, the fact that Irinotecan pathway activation is observed in HPV - tumors but not in HPV + tumors suggests that Irinotecan therapy response might vary by HPV status (Fig. 4b).

In HPV + HNSCC we observed enrichment of cell adhesion and integrin pathways, which have previously been implicated in metastasis [42, 43], consistent with the relatively increased frequency of regional and distant metastasis in HPV + HNSCC. Strikingly, we observed enrichment of immune-related pathways including T-cell activation, interleukin signaling, and interferon $\gamma$ signaling (Fig. 4b) in HPV+ HNSCC. In fact, one of the overexpressed cell surface proteins, PDCD1LG2 (PD-L2), is known to be overexpressed in the T-cell activation pathway, it can bind to PD-1 and regulates T-cell-mediated immune response playing a role in immune escape [44, 45], consistent with our findings of overexpression of PD-1 in HPV + T-cells. These findings suggest a cross-talk between the cancer cells and T-cells in the tumor microenvironment of $\mathrm{HPV}+\mathrm{HNSCC}$ tumors. Among the cell surface genes overexpressed in both subtypes of HNSCC, we observed enrichment for the $\beta 1$ integrin pathway, consistent with previous research targeting this pathway in HNSCC [46] (Fig. 4b, Supplementary Table 6a-c). 
a

Selection criteria of overexpressed genes in HPV + and HPV- HNSCC

20,530 genes from TCGA

RNAseq data

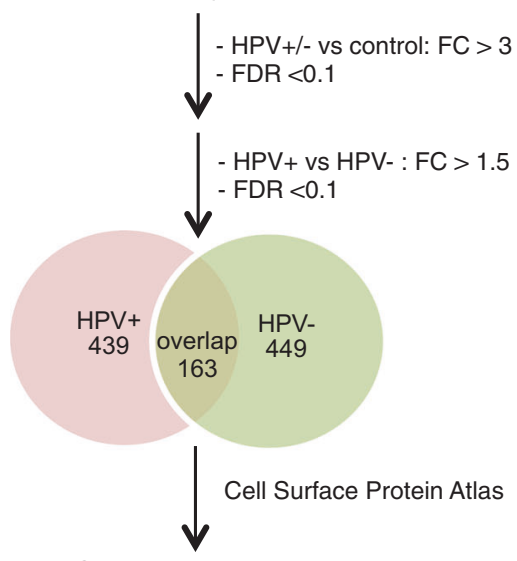

Cell surface proteins

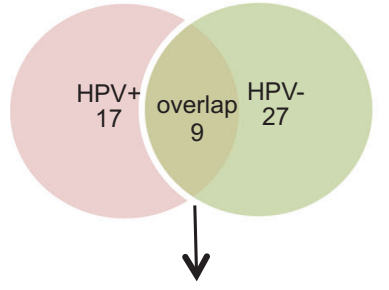

Select candidates for validation based on:

- Expression level in normal tissue <50 TPMGTEx

- Subcellular localization on plasma membrane GeneCards

- Antibodies/primers availability

- Literature review

d

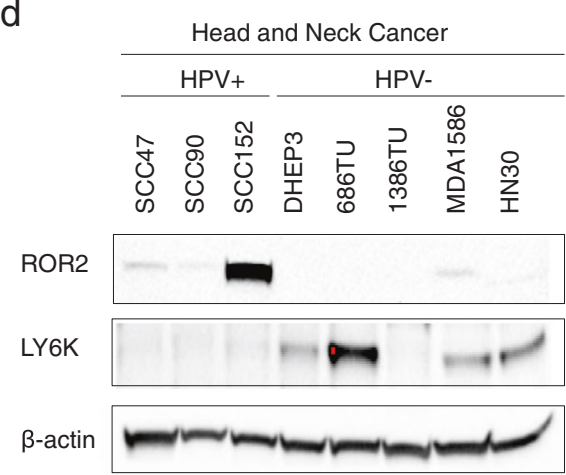

b

Cell surface gene sets upregulated in the cancer cells

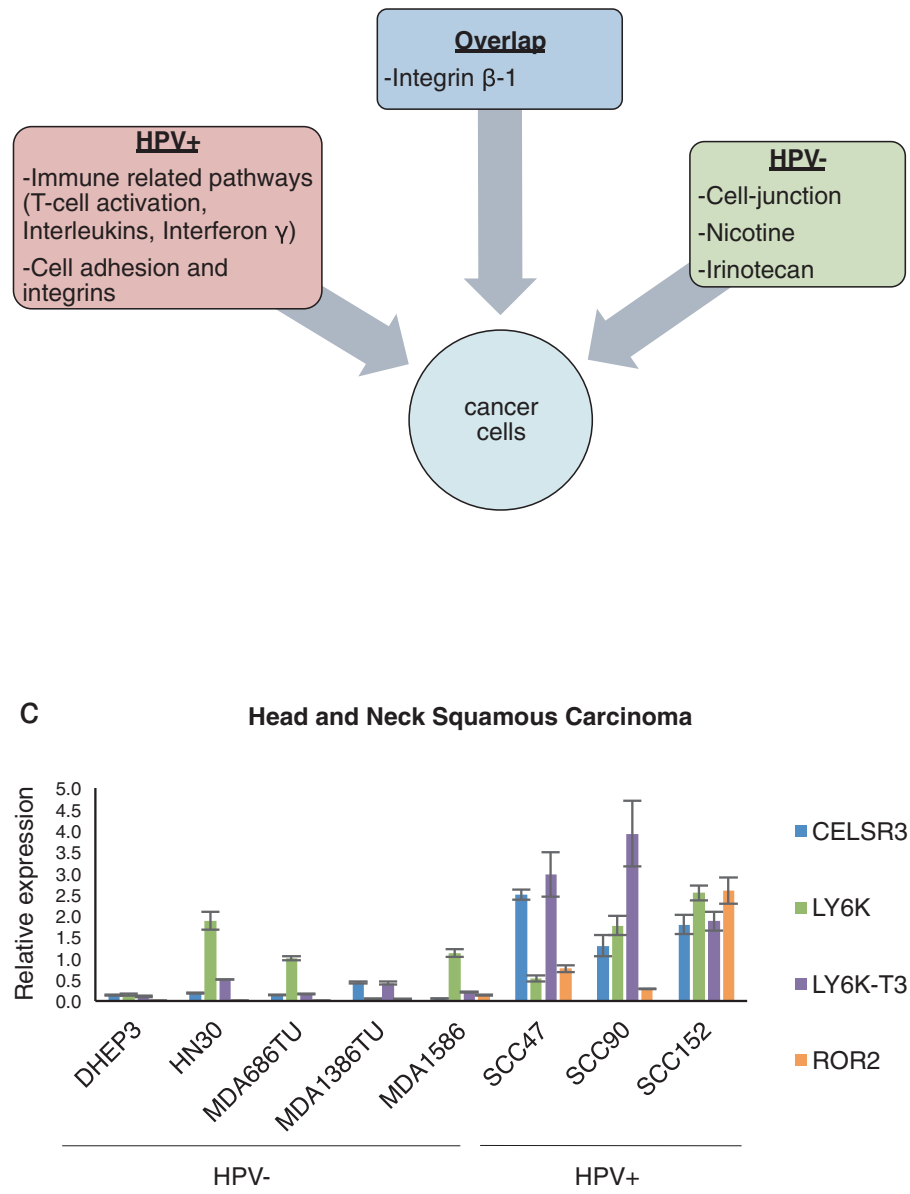

Relative density

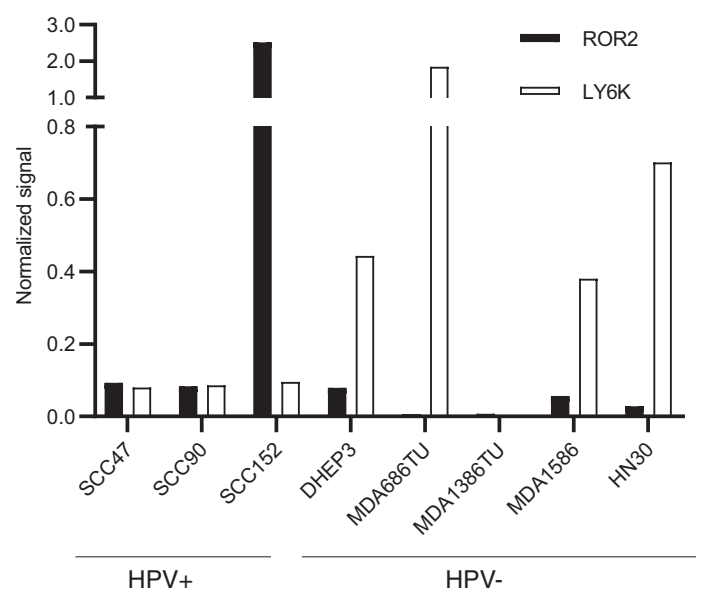

PCR analysis of candidate cell surface genes in HPV + and HPVHNSCC cell lines. d Western blot analysis and the bar graph of relative density after corrected to $\beta$-actin showing expression of ROR2 and LY6K in HPV + and HPV- HNSCC cell lines 


\section{Prioritization of cancer cell surface proteins for validation experiments}

In order to select candidates for validation, we screened the cell surface proteins based on their subcellular localization, expression level in normal tissue according to the GTEx portal from the Broad Institute [47], literature research, and availability of primers/antibodies. The selection process, depicted in Fig. 4a, resulted in the following two types of validation candidates: (1) those highly expressed in both HPV + and HPV - HNSCC: LY6K, and (2) those preferentially expressed in HPV+ HNSC: ROR2, VCAM1, ICAM1, ITGA2B, PTGIR, and CELSR3. In the following two sections, we discuss validation of candidates in both categories.

\section{LY6K as a possible common target for HPV + and HPV - HNSCC}

Transcription of the cancer-testis antigen LY6K was validated in several HPV+ and HPV - HNSCC cell lines (Fig. 4c). LY6K-T3 is the cell surface isoform that has a shorter c-terminal region than other isoforms; however, the biological differences between the three isoforms of LY6K are still unknown. The LY6K transcript variant LY6K-T3 was highly expressed in HNSCC HPV+ cell lines, while LY6K transcript variants 1 and 2 were expressed in both HPV+ and HPV - cell lines. We also observed overexpression of LY6K in HPV+ cervical cancer cell lines (Supplementary Fig. 2a).

We next evaluated protein expression of LY6K by Western blot analysis. LY6K showed higher expression in HPV - when compared to HPV+ HNSCC (Fig. 4d) but showed high expression in HPV + cervical cancer cell lines (Supplementary Fig. 1b). These results suggest that HPVassociated cancers show biological differences depending on the tissue type. The lack of correlation between transcriptome and proteome in HNSCC cell lines might be due to posttranslational modifications or lack of antibodies to discriminate between the different isoforms. Moreover, flow cytometry analyses of HPV + and HPV - HNSCC cell lines showed a pattern of similar expression of LY6K in both subtypes (Supplementary Fig. 3a), suggesting that LY6K could be a potential target for both subtypes of HNSCC.

\section{ROR2 is a potential target for HPV + HNSCC}

Expression of candidates CELSR3 and ROR2 was examined using qRT-PCR in HNSCC cell lines listed in Table 4. We have also examined the expression of these candidate genes in cervical cancer cell lines. We observed overexpression of ROR2 transcripts in HPV + HNSCC cell lines and absence of expression in HPV - cell lines (Fig. 4c).
Interestingly, we observed overexpression of ROR2 in both $\mathrm{HPV}+$ and HPV - cervical cancer cell lines (Supplementary Fig. 2a).

We could not validate protein expression of ICAM-1, VCAM-1, and PTGIR (Supplementary Fig. 3b) using available reagents. These results may also suggest that cell lines might not fully recapitulate protein expression in tumor tissue, possibly due to loss of the cellular microenvironment upon passaging of cancer cells as a monoculture in the 2-D culture system.

Among the list of candidates examined by Western blot, only ROR2 showed higher protein expression in HPV+ HNSCC than in HPV- HNSCC (Fig. 4d). Moreover, ROR2 also showed higher expression in HPV+ cervical cancer cell lines compared to HPV - cervical cancer cell lines (Supplementary Fig. 2b). Although CELSR3 could not be validated by Western blot, flow cytometry analyses showed a trend towards higher expression in HPV+ HNSCC cells (Supplementary Fig. 3a). Taken together, our RNA and protein analyses suggest that ROR2 is preferentially expressed in HPV+ HNSCC and therefore may potentially serve as a target for HPV + HNSCC-specific therapy.

\section{Discussion}

To gain insights into the tumor microenvironments of the HPV + and HPV - HNSCC tumor subtypes and identify potential therapy targets, we performed histoepigenetic analysis of 580 HNSCC tumors from the TCGA dataset. Epigenomic deconvolution revealed their constituent cell types, and potential cancer cell-specific targets. One limitation of our current analyses is the inability to deconvolute normal epithelial from stromal cells, possibly due to high heterogeneity of HNSCC tumors [48].

We identified differences between the epigenomes of HPV + and HPV - cancer cells and also differences in their corresponding microenvironments. By combining the EDec method of epigenomic deconvolution with gene expressionbased MCP Counter analysis, we were able to obtain a more complete assessment of the immune compartment. We observed high abundance of both CD8 T-cells and of B-cells, consistent with previous studies suggesting that Bcells play a role in the priming of CD8 T-cells for activation of immune response [49]. Overall, the immune composition analysis suggests that HPV+ tumors are more immunogenic than HPV - tumors and that CD8 T-cell and B-cell abundance accounts for better survival in HPV+ HNSCC.

We observed enrichment of Type I interferon pathway in HPV - tumors, which plays a double role in cancer, providing signals that help detect and control cancer cells but also in some cases suppressing immune response [50]. These 


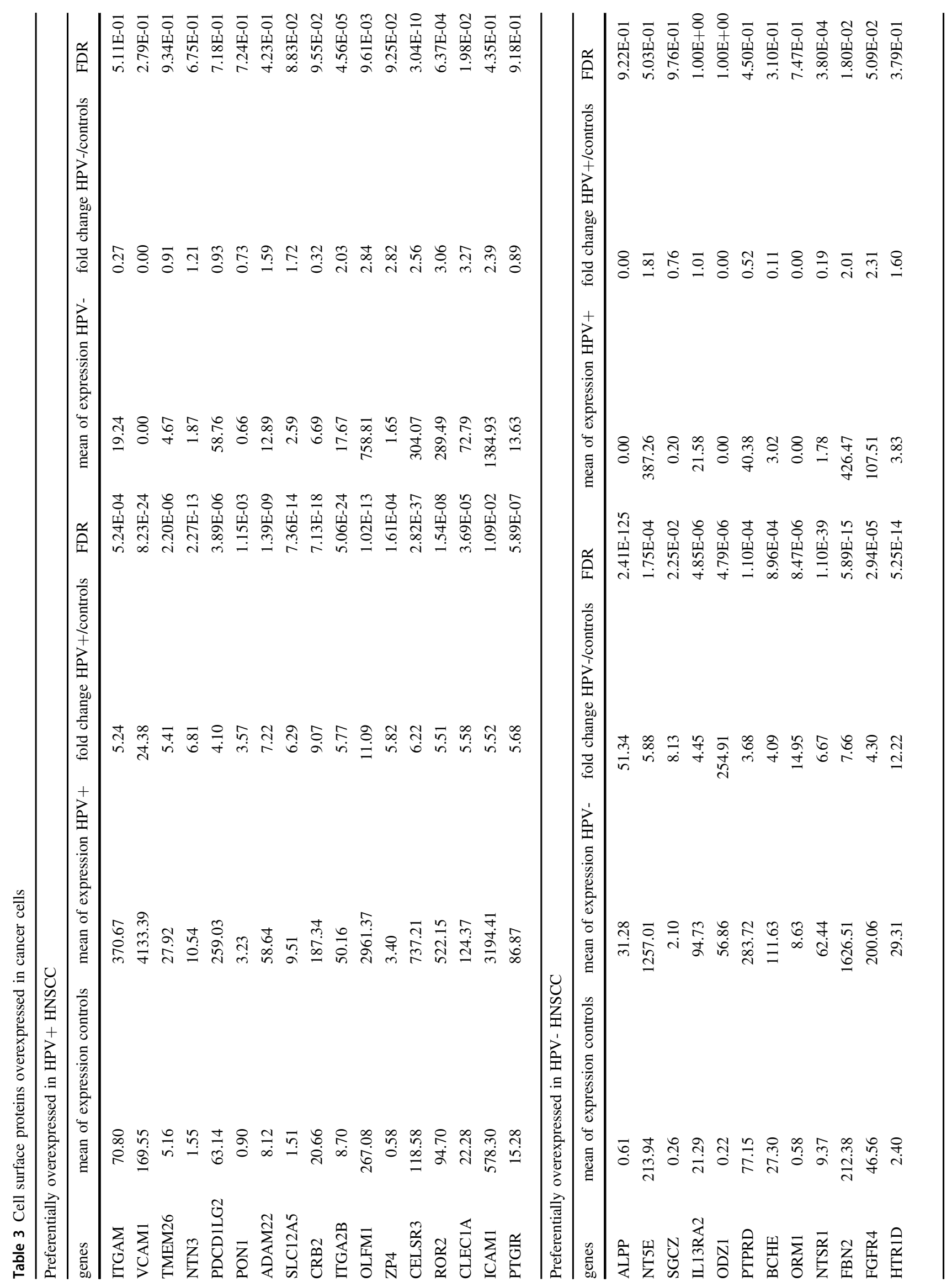




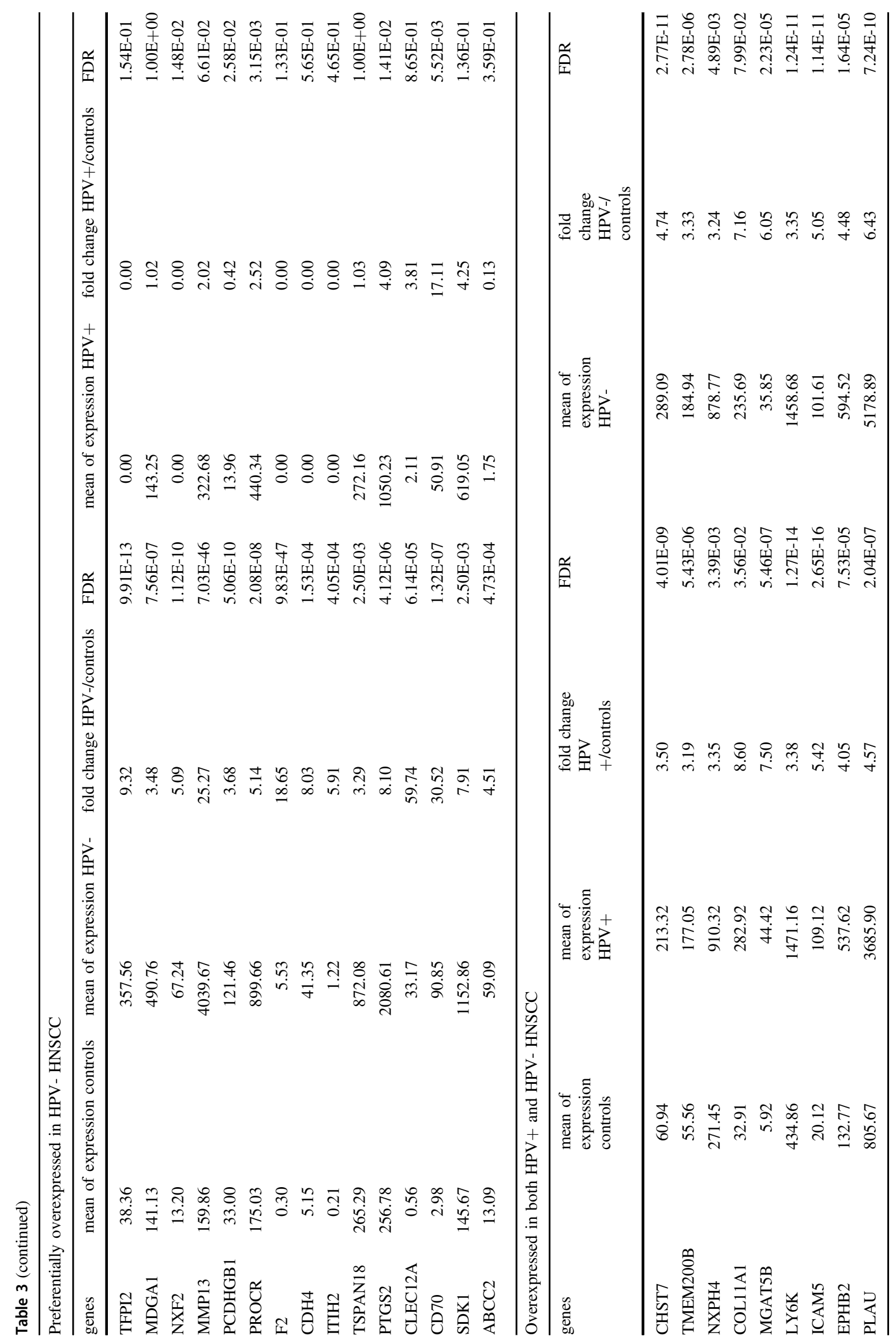


Table 4 Cancer cell lines

\begin{tabular}{lll}
\hline Cell line & Cancer type & HPV status $(+/-)$ \\
\hline DHEP3 & Head and neck & - \\
MDA1386TU & Head and neck & - \\
MDA1586 & Head and neck & - \\
HN30 & Head and neck & - \\
MDA686TU & Head and neck & - \\
UM-SCC-47 & Head and neck & + \\
UPCI:SCC090 & Head and neck & + \\
UPCI:SCC152 & Head and neck & + \\
UPCI:WCC154 & Head and neck & + \\
c-33a & Cervical & - \\
SiHa & Cervical & + \\
Caski & Cervical & + \\
\hline
\end{tabular}

observations suggest that the immune infiltration in HPVtumors may be predominantly suppressive, while in HPV+ tumors the infiltration includes both cell types associated with relatively better prognosis (i.e., $\mathrm{CD} 8+\mathrm{T}$-cells) as well as cell types of uncertain significance (i.e., B c-ells).

Cell-type-specific transcriptome analysis reveals overexpression of PD-1 and PD-L2, a ligand of PD-1 in HPV+ but not in HPV - tumors. In combination with previous findings that detection of both PD-L1 and PD-L2 predict positive response to the drug Pembrolizumab [44], our results suggest that HPV + tumors may be more responsive to therapies targeting PD-1 and its ligands. In contrast, CTLA4 is highly expressed in both subtypes of cancer, suggesting that therapies targeting CTLA4 and its ligands may be beneficial for both subtypes.

We also identified cell surface proteins in cancer cells that may potentially serve as targets for the development of new therapies. Some of these cell surface targets are expressed in both subtypes and some are subtype-specific. Our results implicate LY6K in both HPV+ and HPVsubtypes. LY6K is known to play a role in several cancers [51, 52], including HPV-associated cervical cancer [53]. LY6K is a highly specific target as it is a cancer-testis antigen expressed exclusively in normal reproductive tissues and also in some cancer cells. While the overexpression of LY6K has been previously reported in HNSCC [54], we observe for the first time that overexpression of LY6K transcript 3 correlates with the HPV status. Further studies will be required to elucidate the function of LY6K transcript 3 in HPV + HNSCC.

Another potential target is ROR2, a receptor of the noncanonical Wnt pathway that is expressed specifically in HPV + tumors. Aberrant expression of this pathway has been observed in several cancers [55-57], including tongue squamous cell carcinoma [58]. ROR2 plays a dual role in cancer, as either tumor suppressor or activator depending on the affected tissue [59]. Our observed association of ROR2 with $\mathrm{HPV}+$ status suggests a potential role for non-canonical Wnt pathway in HNSCC, and suggests targeting of ROR2 as a potential therapeutic strategy for HPV+ HNSCC. Such targeted therapies with fewer side effects than cytotoxic chemotherapy are particularly relevant for HPV + HNSCC because of better prognosis and higher importance of quality of life preservation for patients with this tumor subtype.

In conclusion, histoepigenetic analysis of HNSCC revealed differences and commonalities between $\mathrm{HPV}+$ and HPV - subtypes at the molecular, cellular and tissue levels, providing insights into HNSCC biology and information to guide the development of immunotherapy and other precision therapies for HNSCC.

\section{Materials and methods}

\section{EDec method}

To perform deconvolution of HNSCC, we used the previously described EDec method [27]. In brief, EDec is an in silico deconvolution method that estimates cell type composition of tumors and gene expression profiles for the predicted cell types.

EDec stage 1 estimates constituent cell type proportions and methylation profiles of the constituent cell types. EDec stage 2 estimates the gene expression profiles of constituent cell types (Fig. 1a, stage 2) [27].

\section{Reference methylation profiles}

EDec requires a list of loci that are differentially methylated between constituent cell types and thus informative for deconvolution. To obtain the differentially methylated loci that differentiate epithelial, stromal, immune, and cancer epithelial cells, the DNA methylation profiles from previously published datasets were gathered from NCBI GEO database. Our reference 450k array profile DNA methylation dataset includes 273 samples from 10 different studies (Supplementary Table 7).

To identify the informative loci, we applied EDec stage 0 to the reference profiles, using a $p$-value of $10^{-10}$. The final reference methylation set contains 400 informative loci (Fig. 1b).

\section{TCGA datasets}

The TCGA methylation and expression data were downloaded from the University of Santa Cruz cancer browser version 2015.

The 580 DNA methylation profiles were generated using Illumina's Infinium Human Methylation 450k arrays. The 
564 normalized RNA-seq v2 profiles were generated by IlluminaHiSeq. HPV status for $72 \mathrm{HPV}+$ and $243 \mathrm{HPV}-$ samples was obtained from ref. [60].

\section{Selecting the number of cell types for deconvolution}

In order to select the number of cell types for the deconvolution, we applied a stability criterion. Specifically, EDec stage 1 is run with a random subset of $80 \%$ of the TCGA DNA methylation profiles using various numbers of cell types (from 3 to 10). We observed that a five cell-type model showed the best reproducibility of methylation and proportion estimates.

\section{Gene set enrichment analysis of methylation profiles of the cancer cell types estimated by EDec}

Gene set enrichment analysis was performed using GSEA [30]. To perform this analysis, using RnBeads, we selected the top 200 genes with hypermethylated and hypomethylated gene bodies and promoters when comparing HPV + to HPV - tumors. Using GSEA, we selected the top 20 GSEA gene set enrichments with an FDR $<0.05$ for each of the four gene sets identified by RnBeads.

\section{Gene expression profiles of constituent cell types}

To estimate gene expression profiles of constituent cell types, we applied EDec stage 2 to the TCGA RNA-seq profiles and cell type proportions (estimated in stage 1). We applied the method independently to the $72 \mathrm{HPV}+, 243$ HPV - and 20 normal samples that have both DNA methylation data and RNA-seq profiles. To identify genes that are preferentially overexpressed in HPV + and in HPV -, we performed $t$-tests comparing the means of expression in HPV + vs normal samples, and HPV - vs normal samples. The threshold to determine differential expression was FDR $<0.1$, fold change of gene expression cancer vs normal samples $>3$. To identify subtype-specific overexpressed proteins we performed a $t$-test comparing the means of gene expression in HPV + vs HPV-, using a fold change of gene expression $>1.5$ and FDR $<0.1$.

To identify the cell surface proteins, we downloaded the Cell Surface Atlas [61]. Gene set enrichment analysis was performed using consensusPathDB [62] on overexpressed cell surface proteins between HPV + and HPV- HNSCC.

\section{Deconvolution of constituent cell types of the immune compartment}

To determine the abundance of constituent cell types of the immune compartment, we applied the previously described method MCP counter [35] to the TCGA RNA-seq data. To determine that an immune cell type is differentially abundant $(p$-value $<0.05)$ and an immune gene is differentially expressed (fold change $>2$, FDR $<0.1$ ) between $\mathrm{HPV}+$ and $\mathrm{HPV}-, t$-test was performed between HPV + vs normal samples, HPV - vs normal samples. To detect subtype specific overexpressed genes and subtype-specific immune cell-type abundance, a $t$-test was performed between HPV+ vs HPV-.

Kaplan-Meier and Cox regression survival analyses were performed in $\mathrm{R}$ using the packages 'survminer' and 'survival'. Gene set enrichment analysis was performed using GSEA [30] on the genes differentially expressed between HPV + and HPV - HNSCC.

\section{Statistical analyses}

All our statistical analyses were performed using the R programming language and Bioconductor packages. The pairwise correlation analyses were performed with the two sided, Pearson method with a confidence level of 0.95 . The KaplanMeier survival analyses were performed with the $\mathrm{R}$ package 'survminer', using the top and bottom 25\% quartiles of CD8 T-cells and B-cells abundances. The multivariate Cox regression was performed with the $\mathrm{R}$ package 'survival', using the top and bottom $25 \%$ quartiles of abundance for CD8 T-cells and B-cells, we also included as factors the following values: HPV status, age of diagnosis, and cancer stage. The default method 'Efron' was used. The collinearity test was performed with the $\mathrm{R}$ package 'car' to calculate the variance inflation factors (VIF). The generalized linear model was performed using the family binomial (logit).

\section{Validation of transcription of target genes using cancer cell lines}

The HPV- HNSCC cell lines DHEP3 (gift from Dr. Julio A. Aurirre-Ghiso, Icahn School of Medicine at Mount Sinai), MDA1386TU, MDA1586, HN30, MDA686TU (gift from Dr. Jeffery N. Myers, MD Anderson Cancer Center) were grown in DMEM (Sigma-Aldrich), 10\% fetal bovine serum, $100 \mathrm{U} / \mathrm{ml}$ penicillin, $100 \mu \mathrm{g} / \mathrm{ml}$ streptamycin, $1 \%$ non-essential amino acids, $1 \%$ sodium pyruvate and vitamin. The HPV + HNSCC cell lines UM-SCC47, UPCI: SCC090, UPCI:SCC154, and UPCI:SCC152 (gift from Dr. Susanne M. Gollin, University of Pittsburgh) are cultured in MEM with $10 \%$ FBS, non-essential amino acids and gentamicin. They were maintained at $37{ }^{\circ} \mathrm{C}$ with $5 \% \mathrm{CO}_{2}$ in humidified incubator.

Total RNA was extracted using TRIzol reagent (Invitrogen) and the concentration and the purity of RNA were measured by Cytation 3 (BioTek). cDNA was synthesized from $1 \mu \mathrm{g}$ total RNA using qScript cDNA supermix 
(Quanta). The gene-specific PCR products were generated with PerfeCta SYBR Green FastMix (Quanta) and reactions carried out in a CFX96 real-time PCR machine (Bio-Rad). Primer sets for the candidate genes are listed in Supplementary Table 8.

\section{Evaluation of protein expression}

Cell pellets were washed with ice-cold PBS twice then scraped from the T75 flask. Cell pellets were lysed in RIPA buffer (Biosciences), phenylmethanesulfonyl fluoride (PMSF), and cocktail inhibitor 2 (Sigma). Then the proteins $(30 \mu \mathrm{g})$ were resolved by $4-12 \%$ SDS-PAGE pre-cast gels (Invitrogen) and subsequently electrophoretically transferred to PVDF membranes. Membranes were incubated with $3 \%$ BSA of blocking buffer for $1 \mathrm{~h}$ at room temperature then incubated with primary antibodies at $4{ }^{\circ} \mathrm{C}$ overnight. Membranes were incubated with corresponding species of secondary antibodies for $1 \mathrm{~h}$ at room temperature, followed by the detection with the enhanced chemilumiescence (ECL) system (Thermoscientific Fisher) and visualized by ChemiDoc (Bio-Rad). The relative densities of bands were quantified using ImageJ software (NIH). Sources of antibodies were as follows: anti-LY6K (HPA017770, Sigma-Aldrich), anti-CELSR3 (clone: 763103, R\&D Biotechnology), anti- $\beta$-actin, anti-ICAM-1, anti-VCAM-1, antiPTGIR (clone: C4, G5, E10, G7, Santa Cruz Biotechnology), anti-ROR2 (DSHB Hybridoma, University of Iowa).

\section{Disclaimer}

All the authors of this manuscript state the material is original research, has not been previously published and has not been submitted for publication elsewhere while under consideration.

Acknowledgements We are grateful to Rocco Lucero (Baylor College of Medicine) for the differential methylation pathway analysis, to Dr. Julio A. Aurirre-Ghiso (Icahn School of Medicine at Mount Sinai) for providing the DHEP3 cell line, Dr. Jeffery N. Myers (MD Anderson Cancer Center) for providing the MDA1386TU, MDA1586, HN30, MDA686TU cell lines, and Dr. Susanne M Gollin (University of Pittsburgh) for providing the UM-SCC47, UPCI:SCC090, UPCI: SCC154 and UPCI:SCC152 cell lines.

Author contributions AM and AS conceived and supervised the study. $\mathrm{AM}, \mathrm{AS}, \mathrm{IC}$, and HL designed the experiments and analyzed the data. IC performed the head and neck cancer deconvolution, bioinformatics and statistical analyses. HL performed the qRT-PCR, western blots, and flow cytometry analyses. IC wrote the manuscript with help from AM, AS, and HL. All authors reviewed and edited the manuscript.

Funding This work was supported by a grant from the Common Fund of the National Institutes of Health (NIH) (5U54 DA036134) (to A.M.), the Carolyn Weiss Law Foundation for Academic
Excellence (to AS), and the Baylor College of Medicine Dan L. Duncan Cancer Center Pilot Grant (to AS).

\section{Compliance with ethical standards}

Conflict of interest The authors declare that they have no conflict of interest.

Publisher's note: Springer Nature remains neutral with regard to jurisdictional claims in published maps and institutional affiliations.

Open Access This article is licensed under a Creative Commons Attribution 4.0 International License, which permits use, sharing, adaptation, distribution and reproduction in any medium or format, as long as you give appropriate credit to the original author(s) and the source, provide a link to the Creative Commons license, and indicate if changes were made. The images or other third party material in this article are included in the article's Creative Commons license, unless indicated otherwise in a credit line to the material. If material is not included in the article's Creative Commons license and your intended use is not permitted by statutory regulation or exceeds the permitted use, you will need to obtain permission directly from the copyright holder. To view a copy of this license, visit http://creativecommons. org/licenses/by/4.0/.

\section{References}

1. Jemal A, Siegel R, Ward E, Murray T, Xu J, Thun MJ. Cancer Statistics, 2017. CA Cancer J Clin. 2007;57:43-66. https://doi.org/ 10.3322/canjclin.57.1.43.

2. UICC. Locally advanced squamous carcinoma of the head and neck. Rev Cancer Med WHO List Essent Med. 2014;1-8. https://www.who.int/selection_medicines/committees/expert/20/a pplications/HeadNeck.pdf.

3. McKaig RG, Baric RS, Olshan AF. Human papillomavirus and head and neck cancer: epidemiology and molecular biology. Head Neck. 1998;20:250-65.

4. Ragin CCR, Modugno F, Gollin SM. The epidemiology and risk factors of head and neck cancer: a focus on human papillomavirus. J Dent Res. 2007;86:104-14.

5. Chaturvedi AK, Engels EA, Pfeiffer RM, Hernandez BY, Xiao W, $\mathrm{Kim} \mathrm{E}$, et al. Human papillomavirus and rising oropharyngeal cancer incidence in the United States. J Clin Oncol. 2011;29:4294 301. http://www.ncbi.nlm.nih.gov/pubmed/21969503\%5Cn, http:// www.pubmedcentral.nih.gov/articlerender.fcgi?artid $=\mathrm{PMC} 3221528$.

6. Riaz N, Morris LG, Lee W, Chan TA. Unraveling the molecular genetics of head and neck cancer through genome-wide approaches. Genes Dis. 2014;1:75-86.

7. Fakhry C, Westra WH, Li S, Cmelak A, Ridge JA, Pinto H, et al. Improved survival of patients with human papillomavirus-positive head and neck squamous cell carcinoma in a prospective clinical trial. J Natl Cancer Inst. 2008;100:261-9.

8. Afghahi A, Sledge GW. Targeted therapy for cancer in the genomic era. Cancer J. 2015;21:294-8. http://content.wkhealth.com/linkback/ openurl?sid $=$ WKPTLP:landingpage $\&$ an $=00130404-201507000$ 00010.

9. Rieke DT, Klinghammer K, Keilholz U. Targeted therapy of head and neck cancer. Oncol Res Treat. 2016;39:780-6.

10. Mandal R, Şenbabaoğlu Y, Desrichard A, Havel JJ, Dalin MG, Riaz N, et al. The head and neck cancer immune landscape and its immunotherapeutic implications. JCI Insight. 2016;1. https:// insight.jci.org/articles/view/89829 
11. TCGA Network. Comprehensive genomic characterization of head and neck squamous cell carcinomas. Nature. 2015;517:57682. http://www.nature.com/doifinder/10.1038/nature14129.

12. Smith E, Wang D, Kim Y, Rubenstein L, Lee JH, Haugen T. et al. P16INK4a expression, human papillomavirus, and survival in head and neck cancer. Oral Oncol. 2008;44:133-142.

13. Degli Esposti D, Sklias A, Lima SC, Beghelli-de la Forest Divonne S, Cahais V, Fernandez-Jimenez N, et al. Unique DNA methylation signature in HPV-positive head and neck squamous cell carcinomas. Genome Med. 2017;9:33. http://genomemedicine.biomedcentral.com/articles/10.1186/s13073-017-0419-z.

14. Lleras RA, Smith RV, Adrien LR, Schlecht NF, Burk RD, Harris TM. et al. Unique DNA methylation loci distinguish anatomic site and HPV status in head and neck squamous cell carcinoma. Clin Cancer Res. 2013;19:5444-55.

15. Ahmed S, Sami A, Xiang J. HER2-directed therapy: current treatment options for HER2-positive breast cancer. Breast Cancer. 2015;22:101-16.

16. McCormack PL, Keam SJ. Bevacizumab: a review of its use in metastatic colorectal cancer. Drugs. 2008;68:487-506.

17. Wang JP, Wu C-Y, Yeh Y-C, Shyr Y-M, Wu Y-Y, Kuo C-Y, et al. Erlotinib is effective in pancreatic cancer with epidermal growth factor receptor mutations: a randomized, open-label, prospective trial. Oncotarget. 2015;6:18162-73.

18. Orentas RJ, Yang JJ, Wen X, Wei JS, Mackall CL, Khan J. Identification of cell surface proteins as potential immunotherapy targets in 12 pediatric cancers. Front Oncol. 2012;2. http://journal. frontiersin.org/article/10.3389/fonc.2012.00194/abstract.

19. Tagliamonte M, Petrizzo A, Tornesello ML, Buonaguro FM, Buonaguro L. Antigen-specific vaccines for cancer treatment. Human Vaccin Immunother. 2014;10:3332-46.

20. Wang B, Wang T, Cao XL, Li Y. Critical genes in head and neck squamous cell carcinoma revealed by bioinformatic analysis of gene expression data. Genet Mol Res. 2015;14:17406-15.

21. Debey S, Schoenbeck U, Hellmich M, Gathof BS, Pillai R, Zander $\mathrm{T}$, et al. Comparison of different isolation techniques prior gene expression profiling of blood derived cells: impact on physiological responses, on overall expression and the role of different cell types. Pharm J. 2004;4:193-207.

22. Aran D, Sirota M, Butte AJ. Systematic pan-cancer analysis of tumour purity. Nat Commun. 2015;6:8971

23. Gentles AJ, Newman AM, Liu CL, Bratman SV, Feng W, Kim D, et al. The prognostic landscape of genes and infiltrating immune cells across human cancers. Nat Med. 2015;21:938-45.

24. Li Y, Xie X. A mixture model for expression deconvolution from RNA-seq in heterogeneous tissues. BMC Bioinformatics. 2013;14 (Suppl 5):S11. http://www.ncbi.nlm.nih.gov/pubmed/23735186\% $5 \mathrm{Cn}$.

25. Houseman EA, Ince TA. Normal cell-type epigenetics and breast cancer classification: a case study of cell mixture-adjusted analysis of DNA methylation data from tumors. Cancer Inform. 2014;13 (Suppl 4):53-64. http://www.pubmedcentral.nih.gov/articlerender. fcgi? artid $=4264613 \&$ tool $=$ pmcentrez\&rendertype $=$ abstract.

26. Houseman EA, Molitor J, Marsit CJ. Reference-free cell mixture adjustments in analysis of DNA methylation data. Bioinformatics. 2014;30:1431-9.

27. Onuchic V, Hartmaier RJ, Boone DN, Samuels ML, Patel RY, White WM, et al. Epigenomic deconvolution of breast tumors reveals metabolic coupling between constituent cell types. Cell Rep. 2016;17:2075-86.

28. Gutman DA, Cobb J, Somanna D, Park Y, Wang F, Kurc T, et al. Cancer Digital Slide Archive: an informatics resource to support integrated in silico analysis of TCGA pathology data. J Am Med Inform Assoc. 2013;20:1091-8. https://academic.oup.com/jamia/a rticle-lookup/doi/10.1136/amiajnl-2012-001469.
29. Seiwert TY, Zuo Z, Keck MK, Khattri A, Pedamallu CS, Stricker $\mathrm{T}$, et al. Integrative and comparative genomic analysis of HPVpositive and HPV-negative head and neck squamous cell carcinomas. Clin Cancer Res. 2015;21:632-41. http://www.pubmedcentral.nih.gov/articlerender.fcgi?artid $=4305034 \&$ tool $=$ pmcentrez\&rendertype $=$ abstract.

30. Assenov Y, Müller F, Lutsik P, Walter J, Lengauer T, Bock C. Comprehensive analysis of DNA methylation data with RnBeads. Nat Methods. 2014;11:1138-40. http://www.nature.com/ doifinder/10.1038/nmeth.3115.

31. Subramanian A, Tamayo P, Mootha VK, Mukherjee S, Ebert BL. Gene set enrichment analysis: a knowledge-based approach for interpreting genome-wide. Proc Natl Acad Sci USA. 2005;102:15545-50.

32. Mootha VK, Lindgren CM, Eriksson KF, Subramanian A, Sihag $\mathrm{S}$, Lehar J, et al. PGC-1 $\alpha$-responsive genes involved in oxidative phosphorylation are coordinately downregulated in human diabetes. Nat Genet. 2003;34:267-73.

33. Ben-Porath I, Thomson MW, Carey VJ, Ge R, Bell GW, Regev A, et al. An embryonic stem cell-like gene expression signature in poorly differentiated aggressive human tumors. Nat Genet. 2008;40:499-507.

34. Litwin TR, Clarke MA, Dean M, Wentzensen N. Somatic host cell alterations in HPV carcinogenesis. Viruses. 2017;9:206

35. Becht E, Giraldo NA, Lacroix L, Buttard B, Elarouci N, Petitprez $\mathrm{F}$, et al. Estimating the population abundance of tissue-infiltrating immune and stromal cell populations using gene expression. Genome Biol. 2016;17:218. http://genomebiology.biomedcentral. com/articles/10.1186/s13059-016-1070-5x.

36. Tong CCL, Kao J, Sikora AG. Recognizing and reversing the immunosuppressive tumor microenvironment of head and neck cancer. Immunol Res. 2012;54:266-74.

37. Ang KK, Harris J, Wheeler R, Weber R, Rosenthal DI, NguyenTân F. et al. Human papillomavirus and survival of patients with oropharyngeal cancer. N Engl J Med. 2010;363:24-35.

38. Zhang Y, Koneva LA, Virani S, Arthur AE, Virani A, Hall PB. et al. Subtypes of HPV-positive head and neck cancers are associated with HPV characteristics, copy number alterations, PIK3CA mutation, and pathway signatures. Clin Cancer Res. 2016;22:4735-45.

39. Forster MD, Devlin M-J. Immune checkpoint inhibition in head and neck cancer. Front Oncol. 2018;8(August):1-9. https://www. frontiersin.org/article/10.3389/fonc.2018.00310/full.

40. Knights AJ, Funnell APW, Crossley M, Pearson RCM. Holding tight: cell junctions and cancer spread. Trends Cancer Res. 2012;8:61-9.http://www.pubmedcentral.nih.gov/articlerender. fcgi?artid $=3582402 \&$ tool $=$ pmcentrez\&rendertype $=$ abstract.

41. Argiris A, Buchanan A, Brockstein B, Kolesar J, Ghebremichael M, Pins M, et al. Docetaxel and irinotecan in recurrent or metastatic head and neck cancer: a phase 2 trial of the Eastern Cooperative Oncology Group. Cancer. 2009;115:4504-13.

42. Seguin L, Desgrosellier JS, Weis SM, Cheresh DA. Integrins and cancer: regulators of cancer stemness, metastasis, and drug resistance. Trends Cell Biol. 2015;25:234-40.

43. Ganguly KK, Pal S, Moulik S, Chatterjee A. Integrins and metastasis. Cell Adhes andMigration. 2013;7:251-61.

44. Yearley JH, Gibson C, Yu N, Moon C, Murphy E, Juco J, et al. PD-L2 expression in human tumors: Relevance to anti-PD-1 therapy in cancer. Clin Cancer Res. 2017;23:3158-67.

45. Becht E, Giraldo NA, Germain C, de Reyniès A, Laurent-Puig P, Zucman-Rossi $\mathrm{J}$, et al. Immune contexture, immunoscore, and malignant cell molecular subgroups for prognostic and theranostic classifications of cancers. In: Advances in Immunology, Elsevier. Vol. 130. 2016. p. 95-190, Edited by Robert D. Schreiber. 
46. Koshizuka K, Kikkawa N, Hanazawa T, Yamada Y, Okato A, Arai $\mathrm{T}$, et al. Inhibition of integrin $\beta 1$-mediated oncogenic signalling by the antitumor microRNA-29 family in head and neck squamous cell carcinoma. Oncotarget. 2018;9:3663-76. www. impactjournals.com/oncotarget\%0Awww.impactjournals.com/ oncotarget/.

47. Lonsdale J, Thomas J, Salvatore M, Phillips R, Lo E, Shad S, et al. The genotype-tissue expression (GTEx) project. Nat Genet. 2013;45:580-5.

48. Mroz EA, Rocco JW. Intra-tumor heterogeneity in head and neck cancer and its clinical implications. World $\mathrm{J}$ Otorhinolaryngol Neck Surg. 2016;2:60-7. http://linkinghub.elsevier.com/retrieve/ pii/S2095881116300191.

49. Castiglioni P, Gerloni M, Cortez-Gonzales X, Zanetti M. CD8 T cell priming by B lymphocytes is CD4 help dependent. Eur J Immunol. 2005;35:1360-70.

50. Snell LM, McGaha TL, Brooks DG. Type I interferon in chronic virus infection and cancer. Trends Immunol. 2017;38:542-57.

51. Ishikawa $\mathrm{N}$, Takano $\mathrm{A}$, Yasui $\mathrm{W}$, Inai $\mathrm{K}$, Nishimura $\mathrm{H}$, Ito $\mathrm{H}$, et al. Cancer-testis antigen lymphocyte antigen 6 complex locus $\mathrm{K}$ is a serologic biomarker and a therapeutic target for lung and esophageal carcinomas. Cancer Res. 2007;67:11601-11.

52. Kong HK, Yoon S, Park JH. The regulatory mechanism of the LY6K gene expression in human breast cancer cells. J Biol Chem. 2012;287:38889-900. http://www.pubmedcentral.nih.gov/articlerender.fcgi?artid $=3493930 \&$ tool $=$ pmcentrez\&rendertype $=$ abstract.

53. Chen A, Xu Y, Qiu S, Xu K, Zhou L, Li C, et al. LY6K promotes cervical cancer growth, invasion and migration through regulating VEGFA. Int J Clin Exp Pathol. 2016;9:10981-91.

54. De Nooij-Van Dalen AG, GAMS VanDongen, Smeets SJ, EJC Nieuwenhuis, Stigter-Van Walsum M, Snow GB, et al. Characterization of the human Ly-6 antigens, the newly annotated member Ly-6K included, as molecular markers for head-and-neck squamous cell carcinoma. Int J Cancer. 2003;103:768-74.

55. Zhan T, Rindtorff N, Boutros M. Wnt signaling in cancer. Oncogene. 2017;36:1461-73.

56. Voloshanenko O, Schwartz U, Kranz D, Rauscher B, Linnebacher $\mathrm{M}$, Augustin I. et al. $\beta$-cateninindependent regulation of Wnt target genes by RoR2 and ATF2/ATF4 in colon cancer cells. Sci Rep. 2018;8:3178.

57. Clements WM, Wang J, Sarnaik A, Kim OJ, MacDonald J, Fenoglio-Preiser $\mathrm{C}$, et al. $\beta$-catenin mutation is a frequent cause of Wnt pathway activation in gastric cancer. Cancer Res. 2002;62:3503-6.

58. Sakamoto T, Kawano S, Matsubara R, Goto Y, Jinno T, Maruse $\mathrm{Y}$, et al. Critical roles of Wnt5a-Ror2 signaling in aggressiveness of tongue squamous cell carcinoma and production of matrix metalloproteinase- 2 via $\Delta$ Np63 $\beta$-mediated epithelial-mesenchymal transition. Oral Oncol. 2017;69:15-25.

59. Ford CE, Qian MaSS, Quadir A, Ward RL. The dual role of the novel Wnt receptor tyrosine kinase, ROR2, in human carcinogenesis. Int J Cancer. 2013;133:779-87.

60. Nulton TJ, Olex AL, Dozmorov M, Morgan IM, Windle B. Analysis of the cancer genome atlas sequencing data reveals novel properties of the human papillomavirus 16 genome in head and neck squamous cell carcinoma. Oncotarget. 2017;8: 17684-99.

61. Bausch-Fluck D, Hofmann A, Bock T, Frei AP, Cerciello F, Jacobs A. et al. A mass spectrometric-derived cell surface protein atlas. PLoS ONE. 2015;10:e121314.

62. Kamburov A, Pentchev K, Galicka H, Wierling C, Lehrach H, Herwig R. ConsensusPathDB: toward a more complete picture of cell biology. Nucleic Acids Res. 2011;39(Database issue): D712-7. 